\title{
Arthrogryposis, ophthalmoplegia, and retinopathy: confirmation of a new type of arthrogryposis
}

Constance T R M Schrander-Stumpel, Chris J Höweler, Ad B A Reekers, Nicole M A F A De Smet, Judith G Hall, Jean-Pierre Fryns

\begin{abstract}
Arthrogryposis multiplex congenita is a heterogeneous condition and many different types are clinically recognisable. Recently, a new type of autosomal dominant arthrogryposis was described in a father and son. We report on a male patient with similar clinical features, confirming this distinct type of arthrogryposis. The condition is characterised by congenital contractures of the hands and feet with diminished or absent phalangeal creases, ophthalmoplegia, a rigid trunk, deep set eyes, and (in the oldest patient) an abnormal electroretinogram. Differential diagnosis from amyoplasia, the different types of distal arthrogryposis, and symphalangism is discussed. (f Med Genet 1993;30:78-80)
\end{abstract}

Department of Clinical Genetics, Academic Hospital Maastricht, PO Box $1475,6201 \mathrm{BL}$ Maastricht, The Netherlands.

C T R M

Schrander-Stumpel

Department of Neurology, Academic Hospital Maastricht, Maastricht, The

Netherlands.

C J Höweler

\section{Child Rehabilitation} Center,

Franciscusoord, Valkenburg, The Netherlands.

A B A Reekers

Department of Ophthalmology, Maasland Hospital, Sittard, The

Netherlands. N M A F A De Smet

Department of Pediatrics, BC Children's Hospital, Vancouver, Canada. $J$ G Hall

Centre for Human Genetics, University of Leuven, Leuven, Belgium.

J-P Fryns

Correspondence to Dr Schrander-Stumpel.

Received 7 April 1992. Revised version accepted 5 May 1992.
Arthrogryposis multiplex congenita has been defined as "congenital, non-progressive limitation of movement in two or more joints in different body areas". ${ }^{1}$ Over the past 10 years, many different clinical types of arthrogryposis have been delineated ${ }^{2-4}$ and recently an appar-

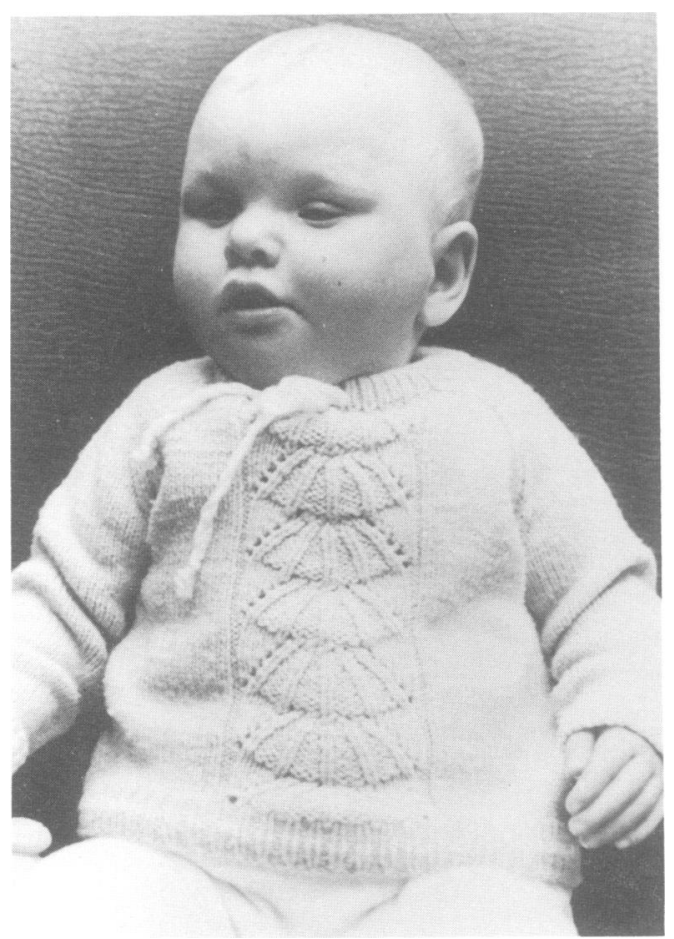

Figure 1 Patient at the age of 8 months showing deep set eyes and stiff fingers. ently new type of arthrogryposis was reported in a father and son. ${ }^{5}$ We had the opportunity to observe the same combination of clinical signs and symptoms in a male patient, confirming the existence of this new entity.

\section{Case report}

The proband is the second son of healthy, nonconsanguineous Dutch parents. His older brother is healthy. Maternal age at the time of birth was 27 years and paternal age 35 years. A cousin (the mother's sister's son) was born with an isolated right club foot. Pregnancy was complicated by hyperemesis gravidarum but no medication was taken. Intrauterine position was constant. The mother did not recall specific details of fetal movement or the amount of amniotic fluid. The birth was normal (exact position not known) at 36 weeks of gestation, birth weight $2700 \mathrm{~g}$. At birth rigid fingers and bilateral club feet were noticed. In the neonatal period a hypertrophic pylorus was surgically treated. Several orthopaedic operations were performed on both feet, the last time being a triple arthrodesis on both feet in 1982. Despite the medical problems psychomotor develop-

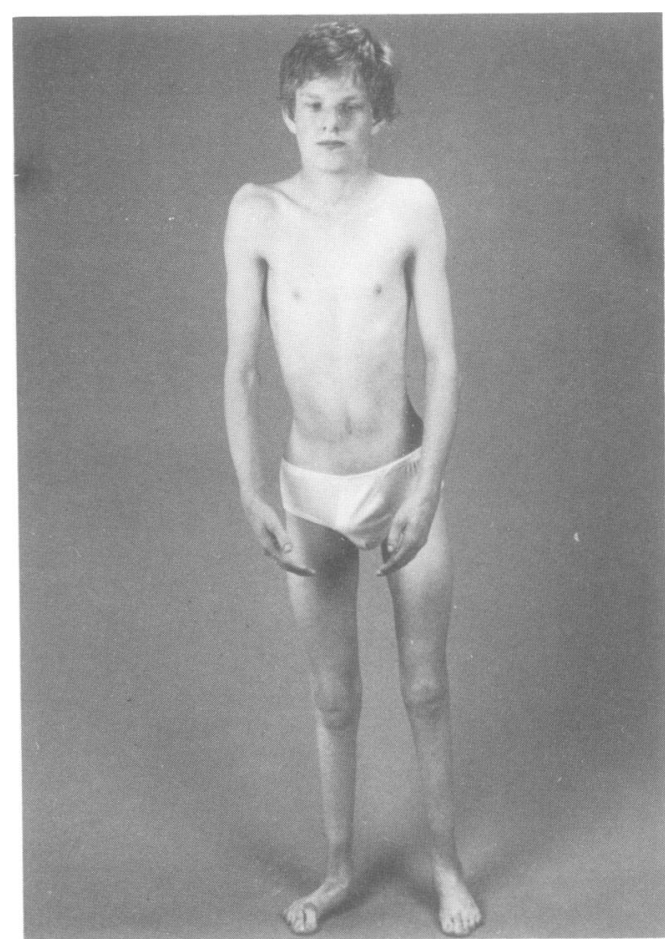

Figure 2 Patient at the age of 17 years showing reduced muscle mass and hunched, anteverted shoulders. 

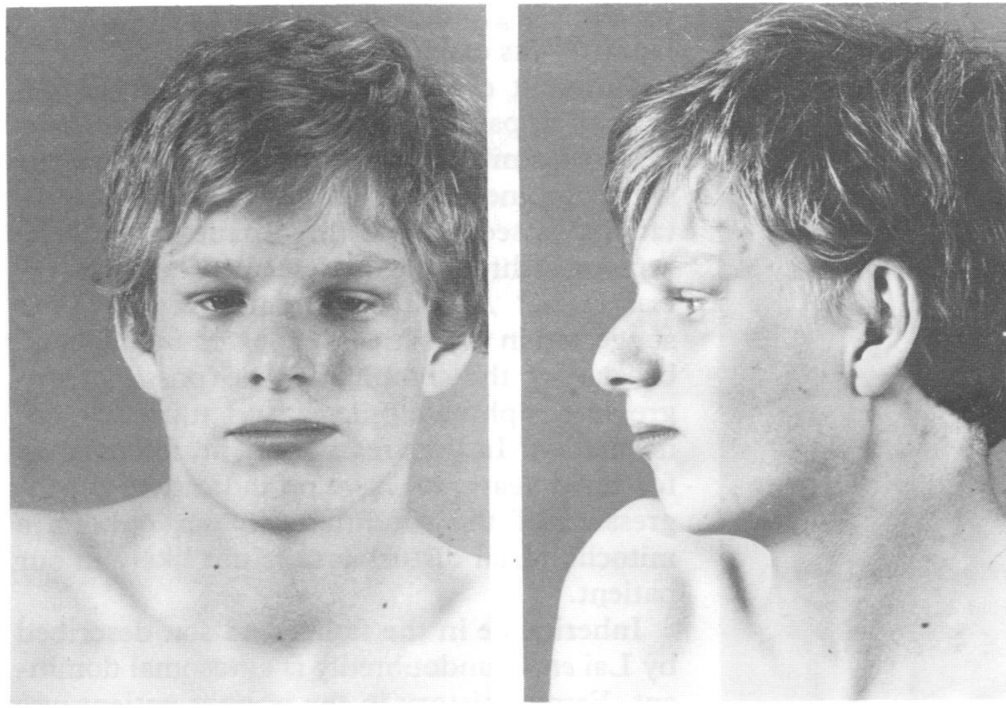

Figure 3 Face and profile of the patient showing the deep set eyes and broad mouth with thin lips.

ment was normal. A family photograph at the age of 8 months showed the deep set eyes and rigid fingers (fig 1). At the age of 6 years he had a triangular face, deep set eyes, and prominent ears. At the age of 17 years the proband was referred for genetic counselling with a diagnosis of 'arthrogryposis multiplex congenita'. On clinical evaluation (fig 2) he was a lean, rigid boy with dry skin. He walked stiffly. Height was $170 \mathrm{~cm}$ (3rd to 10th centile), weight $48 \mathrm{~kg}$ ( $3 \mathrm{rd}$ to 10 th centile for height), and head circumference was $55 \mathrm{~cm}$ (10th centile). Both eyes were deep set and there was ptosis (fig 3). The palpebral fissures measured $2.6 \mathrm{~cm}$ (normal) and inner canthal distance $3.1 \mathrm{~cm}$ (normal). There was little facial expression although motility was normal. He was unable to move his eyes laterally or to look upwards. Muscle mass was reduced especially in the lower limbs; the shoulders were hunched and anteverted and the back was rigid. He had pectus excavatum. The fingers were long and the phalangeal creases were totally absent. Flexion was limited to about $30^{\circ}$

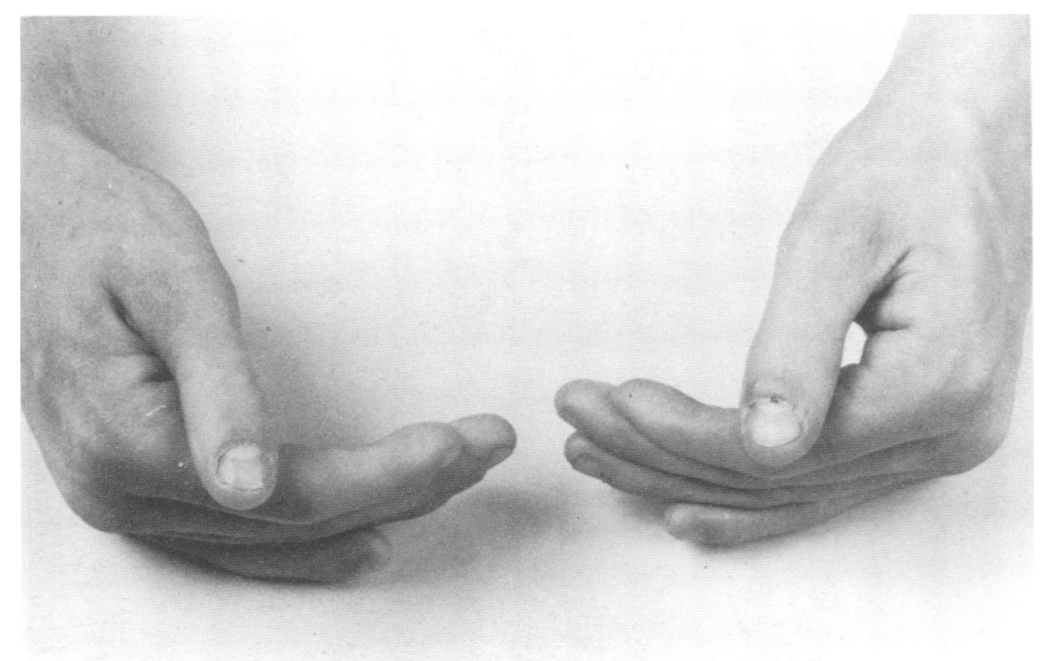

Figure 4 Hands of the patient showing the long fingers at maximal flexion. (fig 4). Both lower legs were thin, the left side more pronounced than the right. The feet showed multiple scars from the orthopaedic surgery. Apart from the ophthalmoplegia, no further neurological abnormalities were found. Intelligence was normal. Ophthalmological investigation showed small eyes with amblyopia in the left eye and 6/10 vision in the right eye. A central scotoma could be seen in both eyes and abnormal pigmentation was present in both retinal maculae. Both eyes showed a Duane anomaly. On electrophysiological examination, the pattern reversal visual evoked response showed less response than normal, but was otherwise unremarkable. The flash visual evoked response was also normal. The electroretinogram failed to give any result because of practical problems (painful test for the patient because of the small, deep set eyes). Chromosomes were normal male 46,XY. Creatine kinase levels were normal. Electromyography showed no neurogenic or myopathic abnormalities and conduction velocities of the nerves were normal. Radiological examination of the vertebral column showed normal vertebrae with limitation of flexion. Radiology of the hands and wrists showed normal carpal bones without fusion, narrow interphalangeal joints, and no bony symphalangism (fig 5). Hearing was normal. CT scan of the brain and orbits showed no abnormalities of the brain and normal eye muscles. CT scan of the muscles of the upper arm, lower arm, thigh, and lower leg showed no abnormalities.

\section{Discussion}

The clinical features of this patient are very similar to those in the father and son reported by Lai $e t a l^{5}$ (table). The facial resemblance of the son and the present patient at the age of 6 years is striking.

For the differential diagnosis, amyoplasia, distal arthrogryposis, and symphalangism were considered in the present patient. The reduced muscle mass, the hunched, anteverted shoulders, the stiffness of the spine, and the club feet were very suggestive of amyoplasia; this diagnosis was initially made in the father described by Lai et al. ${ }^{5}$ The ophthalmoplegia, deep set eyes, ptosis, and retinopathy, however, are incompatible with this diagnosis. ${ }^{4}$ In the distal arthrogryposes, a type I and type II have been delineated. ${ }^{3}$ In type I no associated anomalies are present, intelligence is normal, and inheritance is autosomal dominant. In type II subdivisions have been made (type IIA-E) according to the different associated findings. Presumed new forms of type II distal arthrogryposis have since been reported but we could not fit the clinical data of our patient into any of the clinical types of distal arthrogryposis. $^{67}$

Symphalangism can be defined as bony or fibrous ankylosis of interphalangeal joints resulting in a rigid digit. ${ }^{8}$ In our opinion, bony fusion is mandatory for the diagnosis of symphalangism in an isolated patient. In the present patient the interphalangeal joints were narrow but the phalanges were not fused, thus 


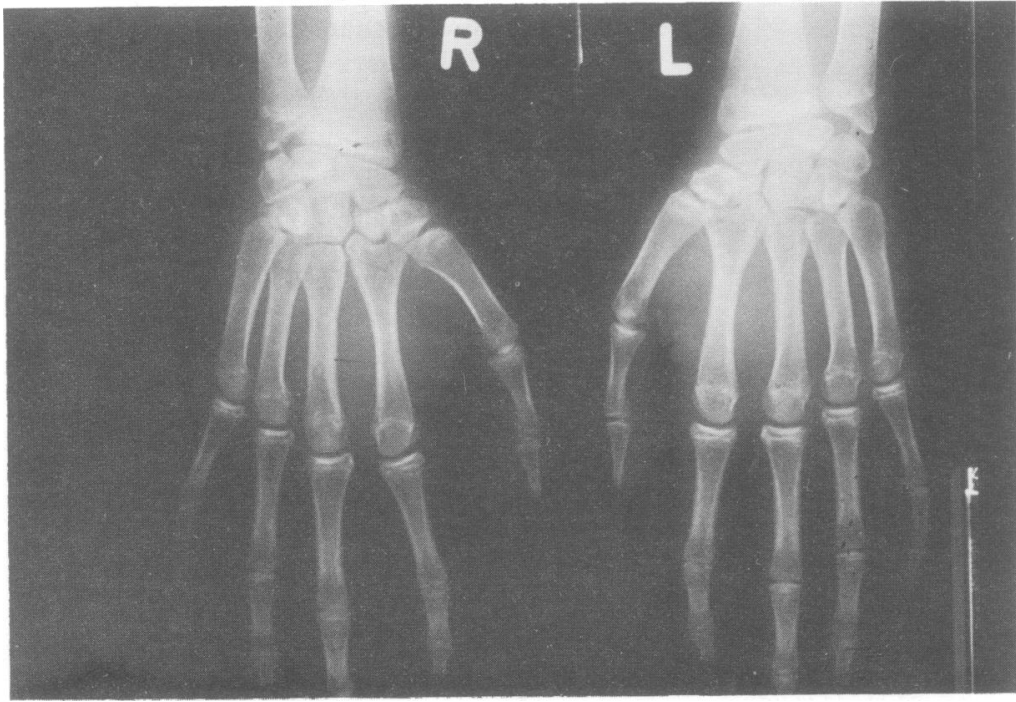

Figure $5 X$ ray of the hands showing the small interphalangeal joints.

Clinical features of the three patients with a new type of arthrogryposis.

\begin{tabular}{lccc}
\hline Clinical symptoms & Patient $1^{5}$ & Patient $2^{5}$ & Patient 3 (this report) \\
\hline Sex & Male & Male & Male \\
Age at diagnosis (y) & 27 & $1 \cdot 5$ & 18 \\
Normal growth & + & + & + \\
Normal intelligence & + & + & + \\
Reduced muscular mass & + & + & + \\
Camptodactyly of fingers & + & + & + \\
Long fingers & $?$ & + & + \\
Absent phalangeal creases & $?$ & + & + \\
Poorly formed palmar creases & $?$ & + & + \\
Limited extension of wrists & + & + & + \\
Limited rotation of forearm & + & + & + \\
Limited extension of large joints & + & + & + \\
Dimples over large joints & + & + & + \\
Anteverted shoulders & + & + & + \\
Hunched shoulders & + & + & + \\
Stiff trunk & + & + & + \\
Pectus deformity & + & + & + \\
Contractures of feet & + & + & + \\
Triangular face & - & + & + \\
Deep set eyes & - & + & + \\
Prominent ears & + & - & + \\
Ophthalmopleiga & + & + & + \\
Abnormal electroretinogram & + & + & + \\
Abnormal retinal pigmentation & + & + & +
\end{tabular}

on clinical grounds the diagnosis of symphalangism was excluded.

Different eye abnormalities have been described in patients with arthrogryposis multiplex congenita ${ }^{9}$ but we could find no patients who combine the eye anomalies and joint limitations as seen in the three patients with the type of arthrogryposis described here and by Lai et al. ${ }^{5} \mathrm{~A}$ mitochondrial myopathy was suggested in the patients reported by Lai et al ${ }^{5}$ because of the combination of (possibly progressive) ophthalmoplegia and muscular abnormality..$^{5}$ In the present patient, followed up for three years, we have no indication of progression of the condition. In our opinion a mitochondrial disturbance is not likely in our patient.

Inheritance in the father and son described by Lai $e t a l^{5}$ undoubtedly is autosomal dominant. Family history in the present patient was not informative although a maternal cousin had serious unilateral club foot. No clinical signs of the condition were found in the parents and the healthy brother. Paternal age at the time of birth was 35 years, suggesting a new dominant mutation in the patient.

1 Hall JG. Nicht-chromosomal bedingte dysmorphie syndrome. Klin Gen Paediatr Mainz Symposium 1980;1:105drom.

2 Hageman G, Jennekens FGI, Vette JK, Willemse J. The heterogeneity of distal arthrogryposis. Brain Dev 1984;6:273-83.

3 Hall JG, Reed SD, Greene G. The distal arthrogryposes: delineation of new entities - review and nosologic discussion. Am F Med Genet 1982;11:185-239.

4 Hall JG, Reed SD, Driscoll EP. Amyoplasia: a common sporadic condition with congenital contractures. Am $\mathscr{J}$ Med Genet 1983;15:571-90.

5 Lai MMR, Tettenborn MA, Hall JG, Smith LJ, Berry AC. A new form of autosomal dominant arthrogryposis. $\mathcal{F} \mathrm{Med}$ Genet 1991;28:701-3.

6 Reiss JA, Sheffield LJ. Distal arthrogryposis type II. A family with varying congenital abnormalities. $A m$ f $\mathrm{Med}$ Genet 1986;24:255-67.

7 Moore CA, Weaver DD. Familial distal arthrogryposis with craniofacial abnormalities: a new subtype of type II? $A m \mathcal{F}$ Med Genet 1989;33:231-7.

8 Matthews S, Farnish S, Young ID. Distal symphalangism with involvement of the thumbs and great toes. Clin Genet with involvement

9 Zeiter JH, Boniuk M. Ophthalmologic findings associated with arthrogryposis multiplex congenita: case report and review of the literature. $\mathcal{F}$ Pediatr Ophthalmol Strab 1989;26:204-8. 